\title{
Remote Stereocontrol by Sulfinyl Groups: Reduction of $\delta$-Ketosulfoxides.
}

José L. García Ruano,* M. Ángeles Fernández-Ibáñez, M. Carmen Maestro*

and M. Mercedes Rodríguez-Fernández.

Departamento de Química Orgánica, Universidad Autónoma de Madrid, Cantoblanco, 28049-

Madrid,SPAIN

joseluis.garcia.ruano@uam.es; carmen.maestro@uam.es.

\section{Supporting Information}

General Experimental Methods and ${ }^{1} \mathrm{H}$ NMR, and ${ }^{13} \mathrm{C}$ NMR spectra of selected compounds (18

pages)

\section{Table of Contents for Supporting Information:}

S1 General Methods

S2 ${ }^{1} \mathrm{H}$ NMR and ${ }^{13} \mathrm{C}$ NMR spectrum of compound $\mathbf{4 a}$

S3 ${ }^{1} \mathrm{H}$ NMR and ${ }^{13} \mathrm{C}$ NMR spectrum of compound 5a

S4 ${ }^{1} \mathrm{H}$ NMR and ${ }^{13} \mathrm{C}$ NMR spectrum of compound $\mathbf{4 b}$

S5 ${ }^{1} \mathrm{H}$ NMR and ${ }^{13} \mathrm{C}$ NMR spectrum of the mixture of compounds $\mathbf{4 b}+\mathbf{5 b}$

S6 ${ }^{1} \mathrm{H}$ NMR and ${ }^{13} \mathrm{C}$ NMR spectrum of compound $4 \mathrm{c}$

S7 ${ }^{1} \mathrm{H}$ NMR and ${ }^{13} \mathrm{C}$ NMR spectrum of compound $\mathbf{5 c}$

S8 ${ }^{1} \mathrm{H}$ NMR and ${ }^{13} \mathrm{C}$ NMR spectrum of compound $\mathbf{4 d}$

S9 ${ }^{1} \mathrm{H}$ NMR and ${ }^{13} \mathrm{C}$ NMR spectrum of the mixture of compounds $\mathbf{4 d}+\mathbf{5 d}$

S10 ${ }^{1} \mathrm{H}$ NMR and ${ }^{13} \mathrm{C}$ NMR spectrum of compound $\mathbf{6 a}$

S11 ${ }^{1} \mathrm{H}$ NMR and ${ }^{13} \mathrm{C}$ NMR spectrum of compound $\mathbf{6 b}$

S12 ${ }^{1} \mathrm{H}$ NMR and ${ }^{13} \mathrm{C}$ NMR spectrum of compound $\mathbf{6 c}$

S13 ${ }^{1} \mathrm{H}$ NMR and ${ }^{13} \mathrm{C}$ NMR spectrum of compound $\mathbf{6 d}$

S14 ${ }^{1} \mathrm{H}$ NMR and ${ }^{13} \mathrm{C}$ NMR spectrum of compound $7 \mathbf{a}$

S15 ${ }^{1} \mathrm{H}$ NMR and ${ }^{13} \mathrm{C}$ NMR spectrum of compound $\mathbf{8 a}$

S16 ${ }^{1} \mathrm{H}$ NMR and ${ }^{13} \mathrm{C}$ NMR spectrum of compound 9a

S17 ${ }^{1} \mathrm{H}$ NMR and ${ }^{13} \mathrm{C}$ NMR spectrum of compound 10a

S18 ${ }^{1}$ H NMR spectrum of compound $\mathbf{1 1}$

\section{General Experimental Methods}

NMR spectra were obtained in $\mathrm{CDCl}_{3}$ solutions at 300 and $75 \mathrm{MHz}$ for ${ }^{1} \mathrm{H}$ and ${ }^{13} \mathrm{C} \mathrm{NMR}$, respectively ( $J$ values are given in hertz). Melting points were measured in open capillary tubes and are uncorrected. Mass spectra (MS) were obtained by EI with ionizing voltage of $70 \mathrm{eV}$. Ed's were evaluated by integration of well-separated signals of the NMR spectra. All reductions were carried out under argon atmosfere in anhydrous solvents. THF was distilled from sodium-benzofenone under argon. Flashcolumn chromatography was perfomed using ${ }_{\mathrm{S} 1}$ silica gel (230-400 mesh). 

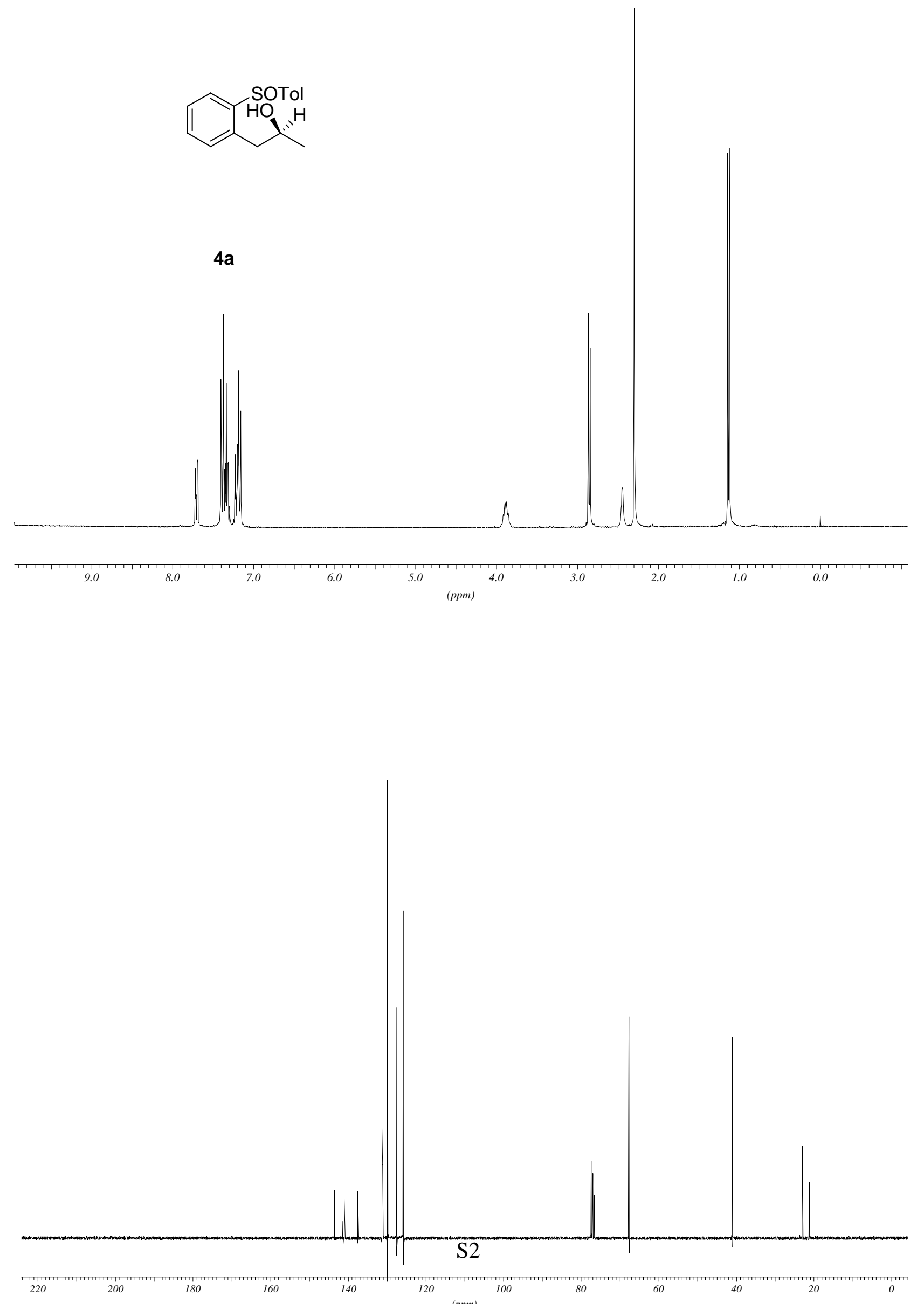

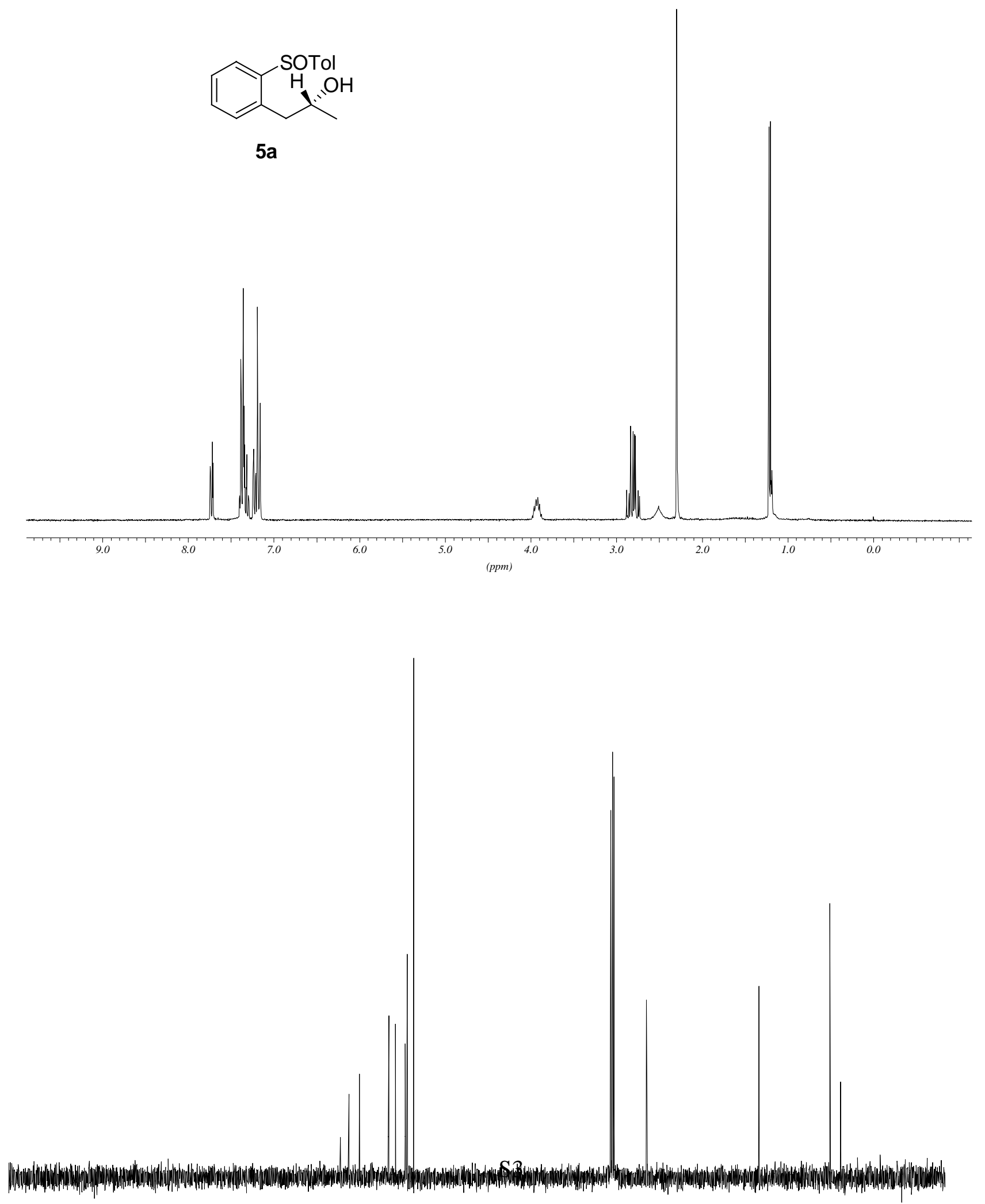

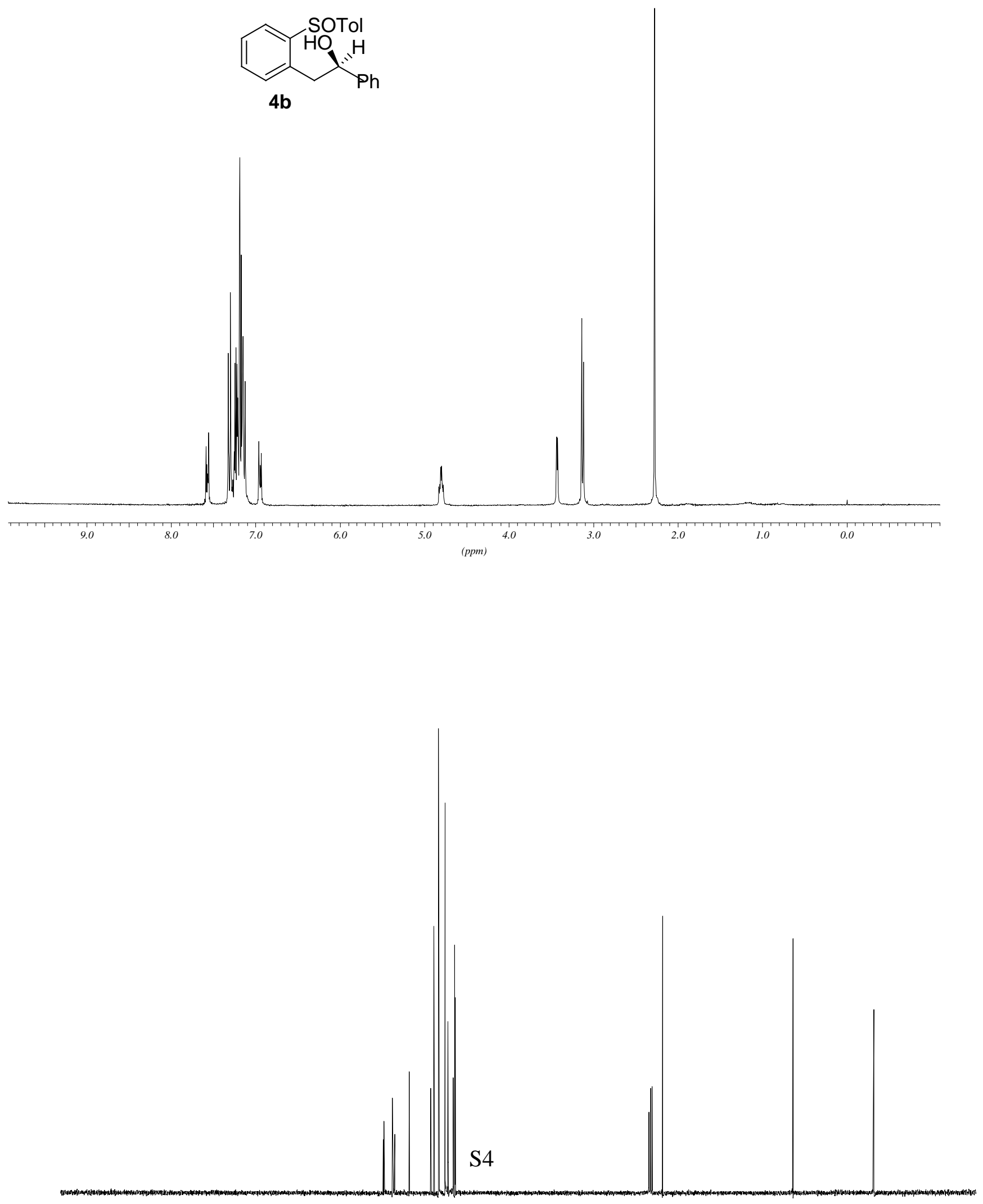


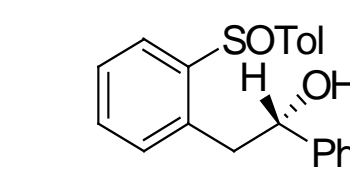

$5 b$<smiles></smiles>

$4 b$
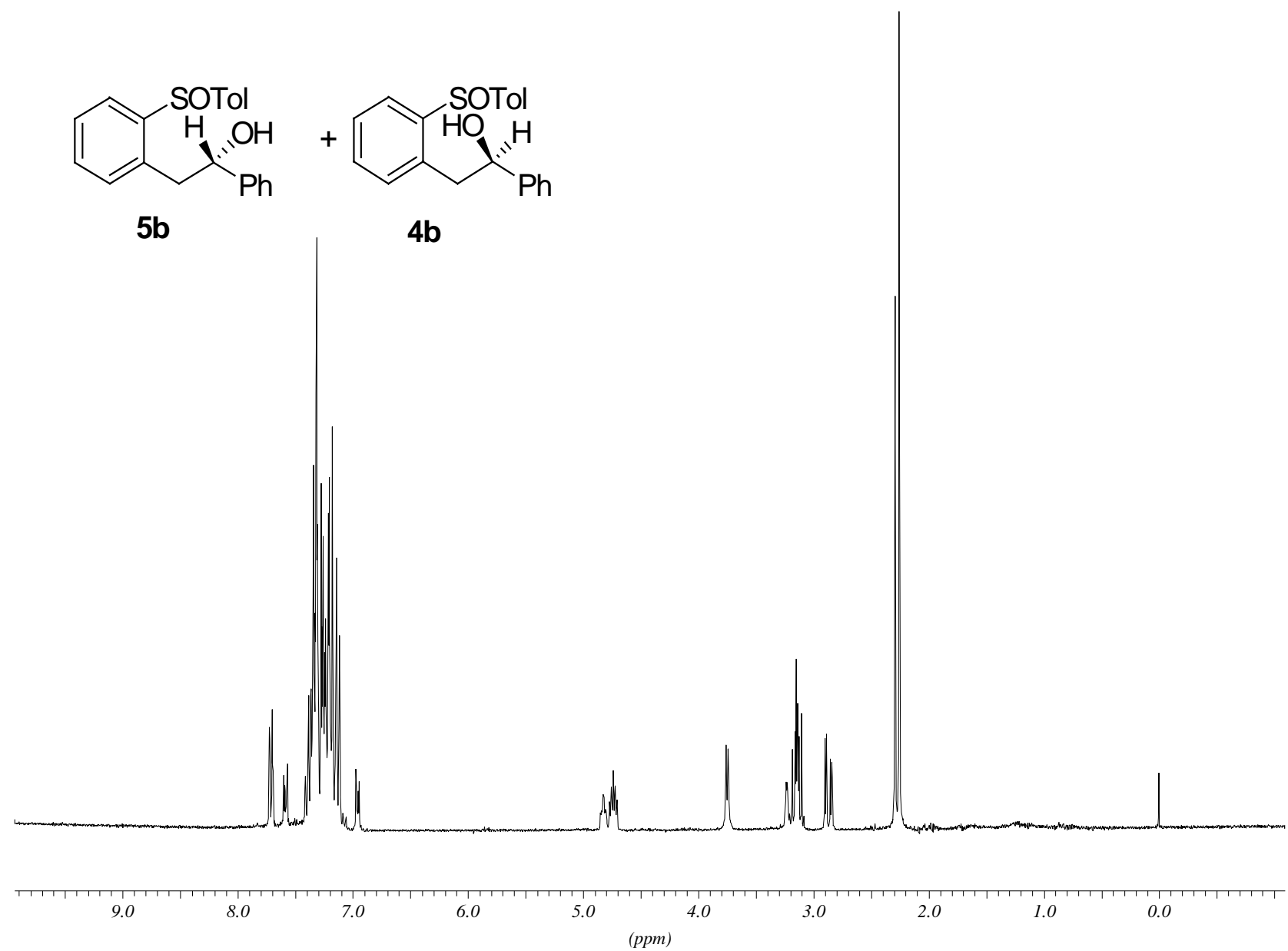

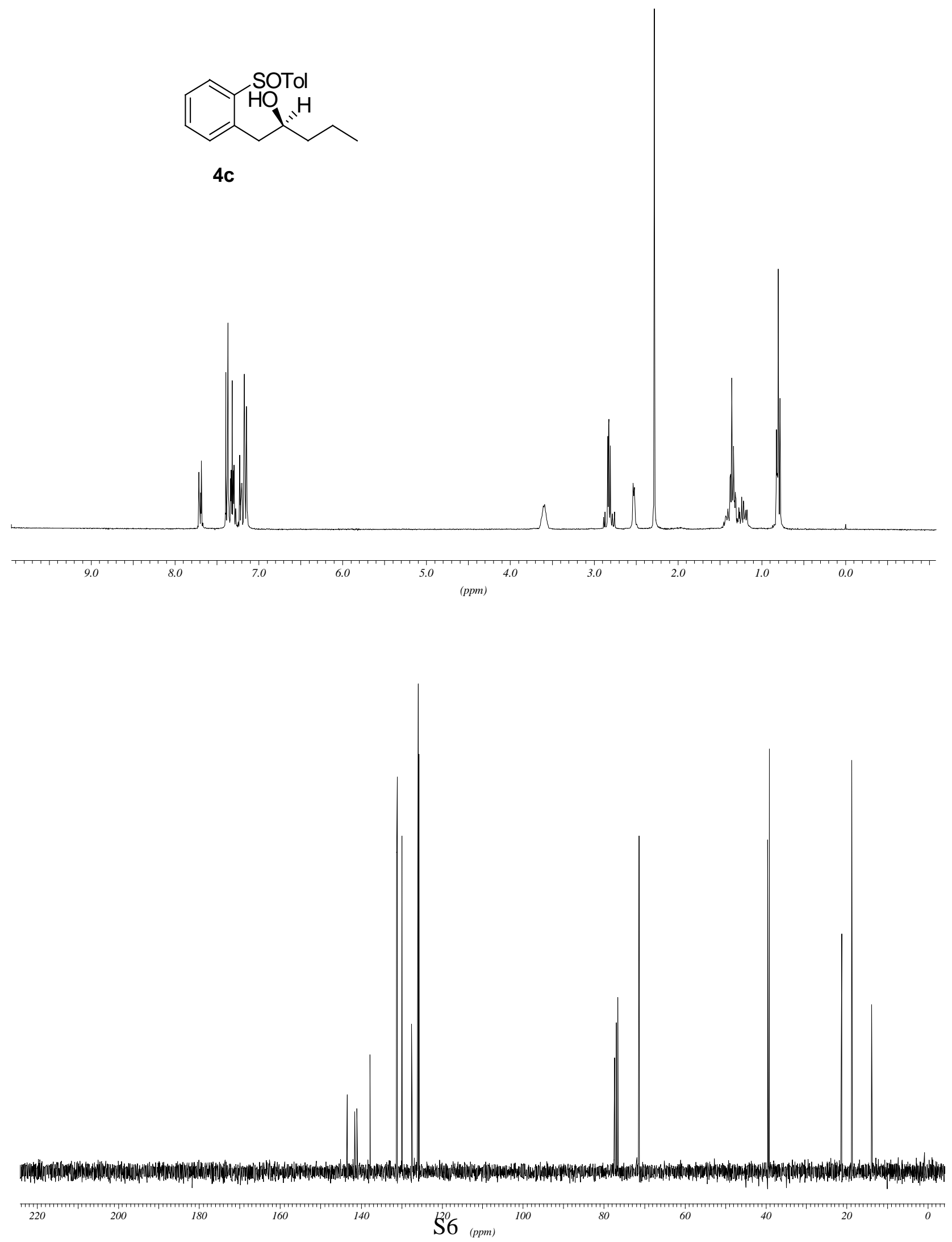


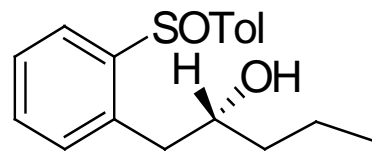

5c
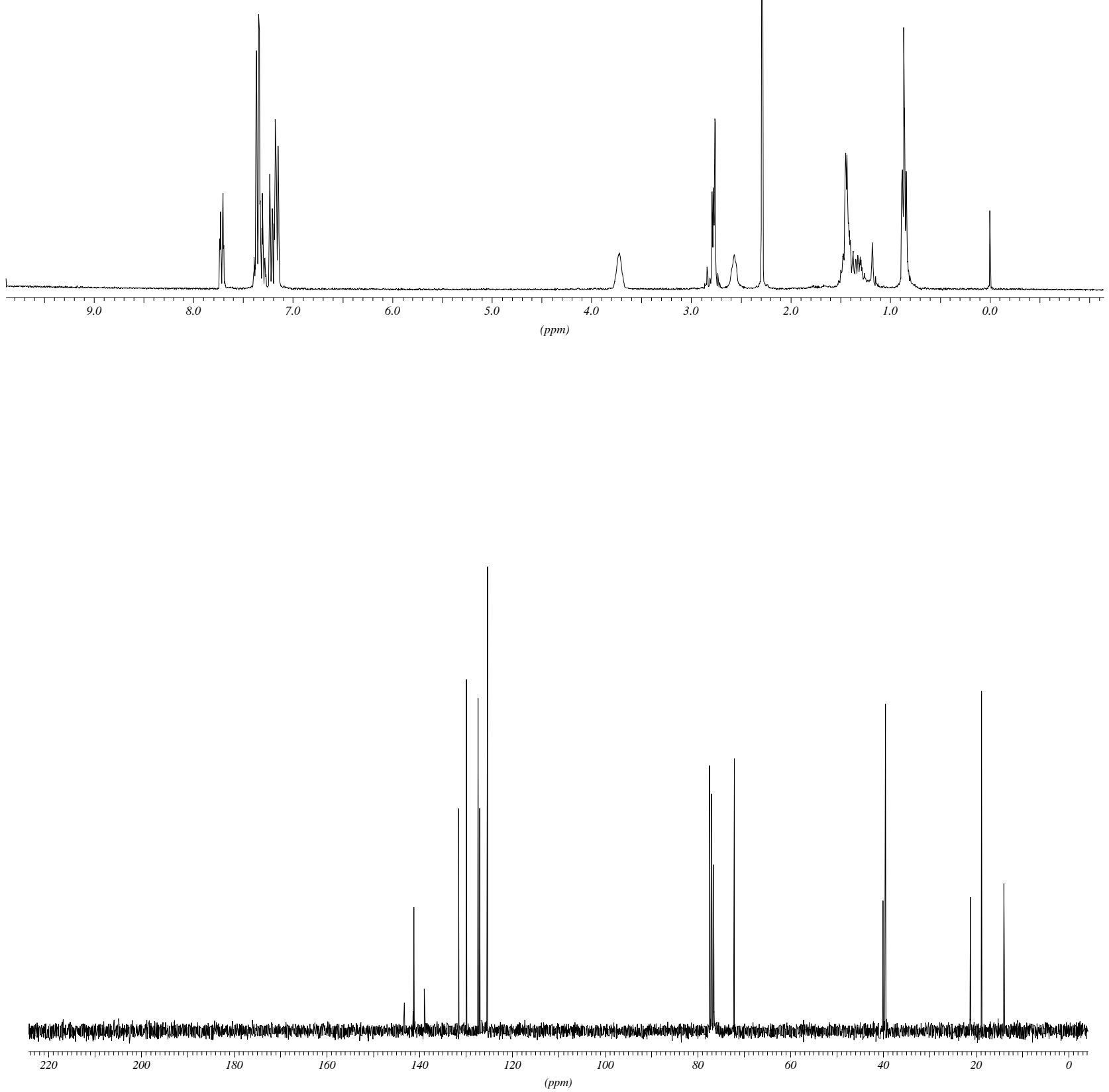

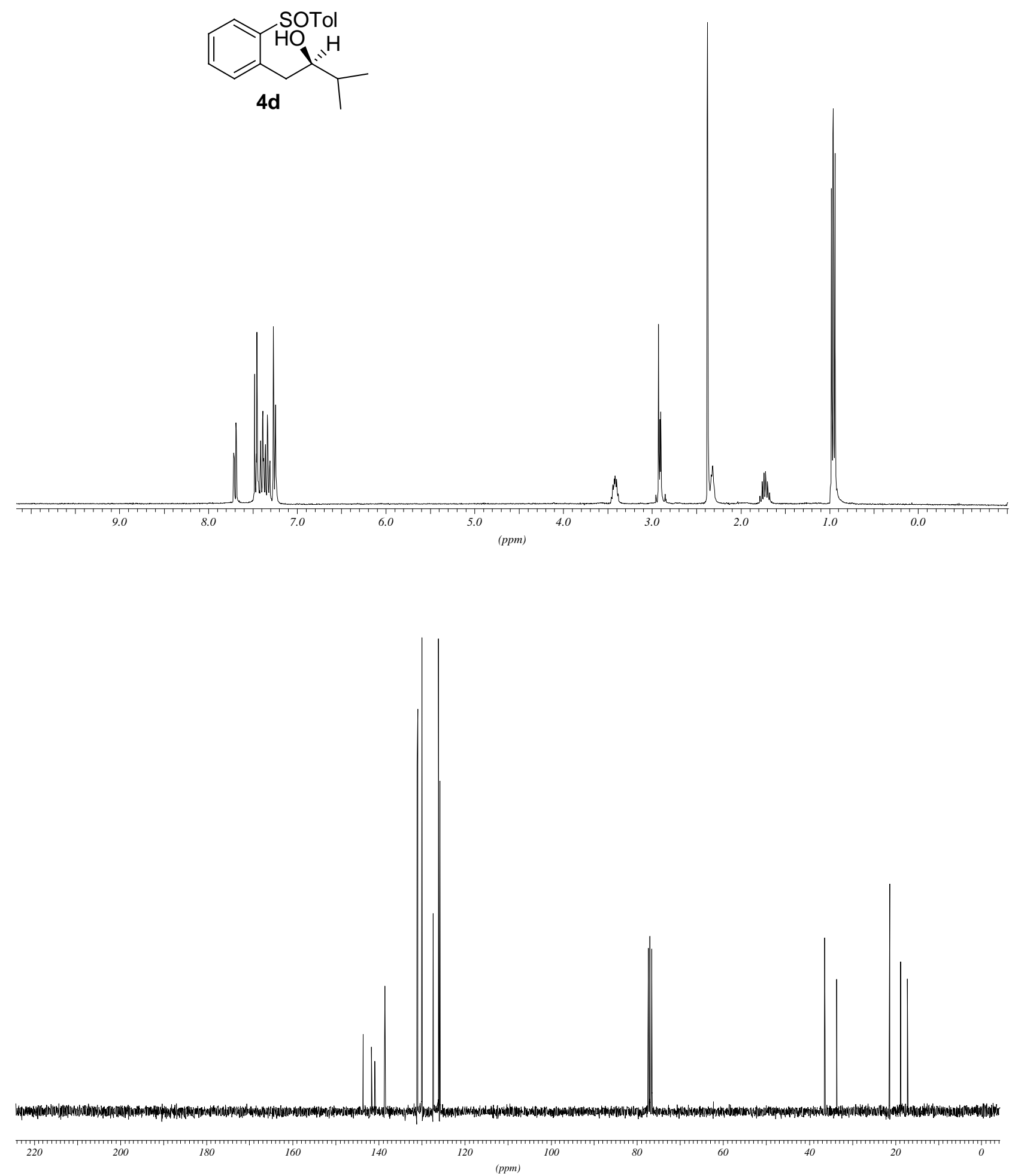

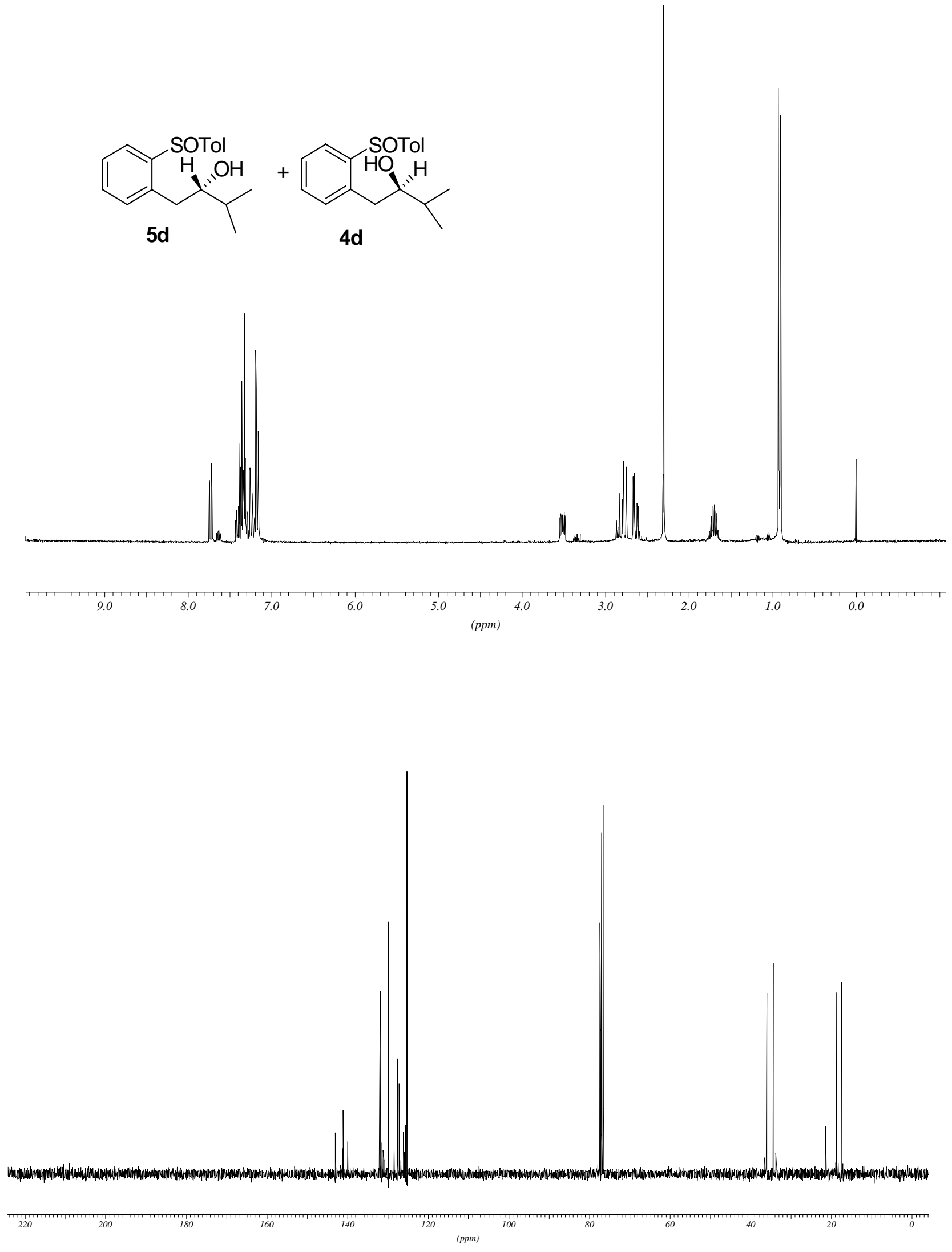

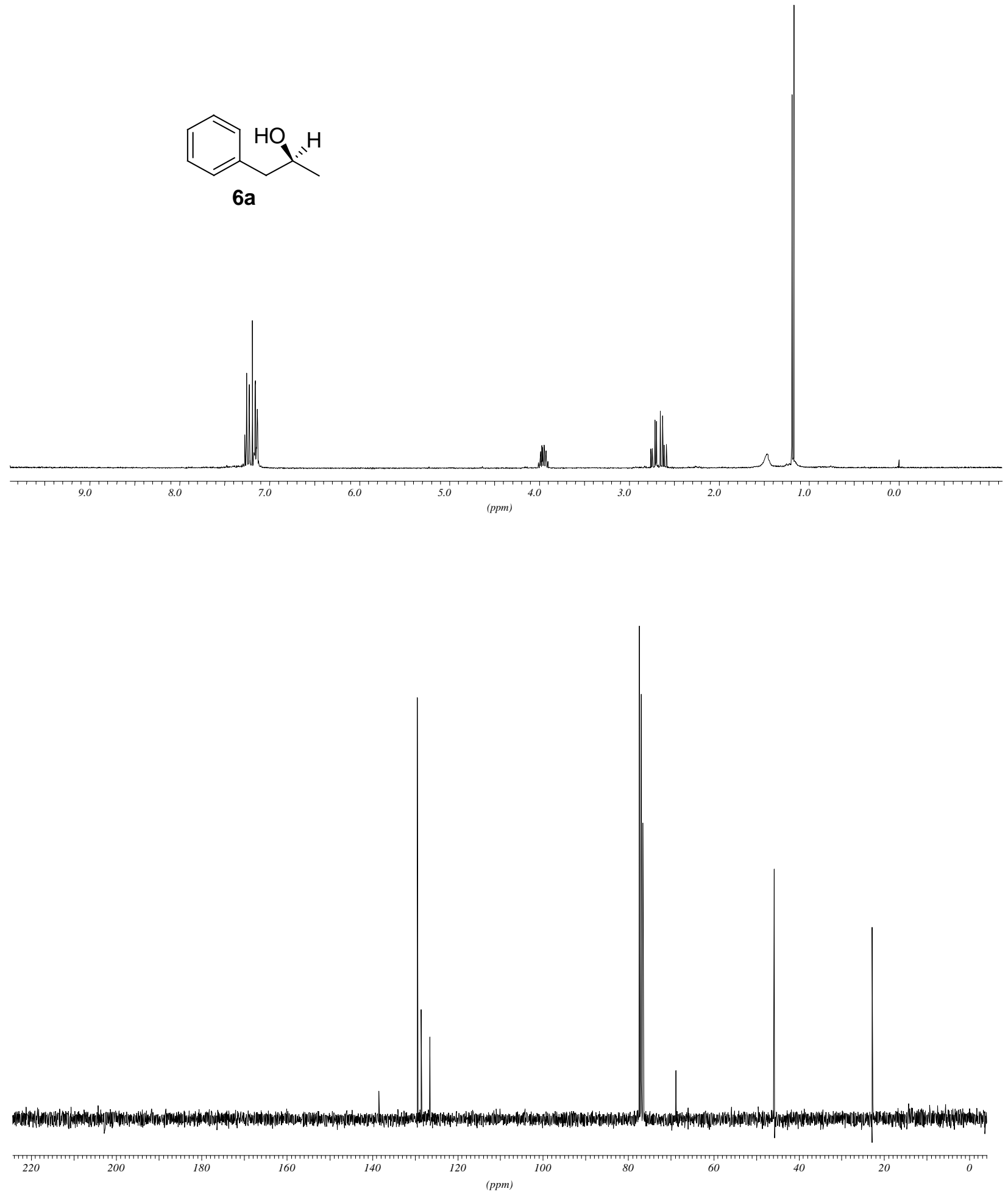

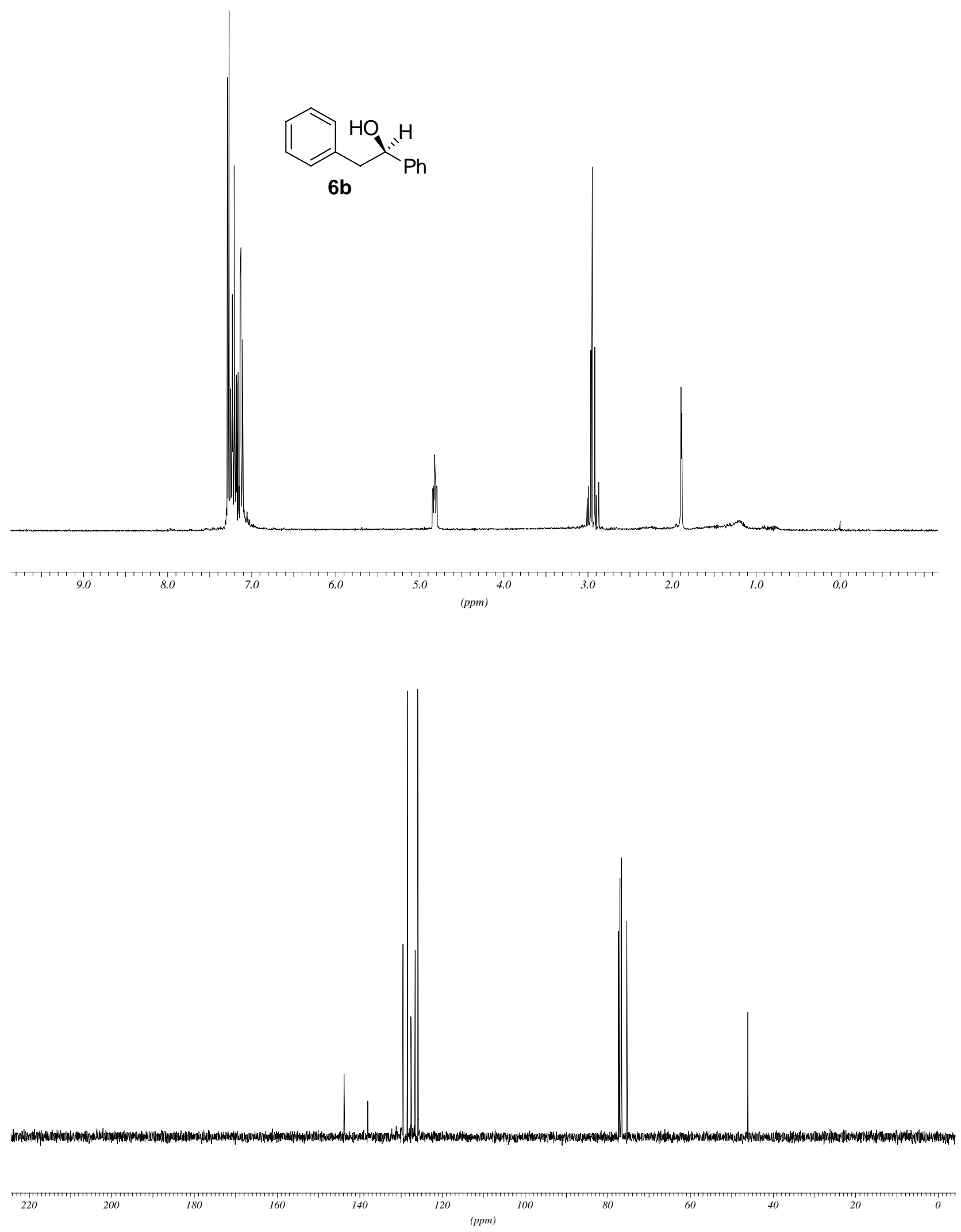

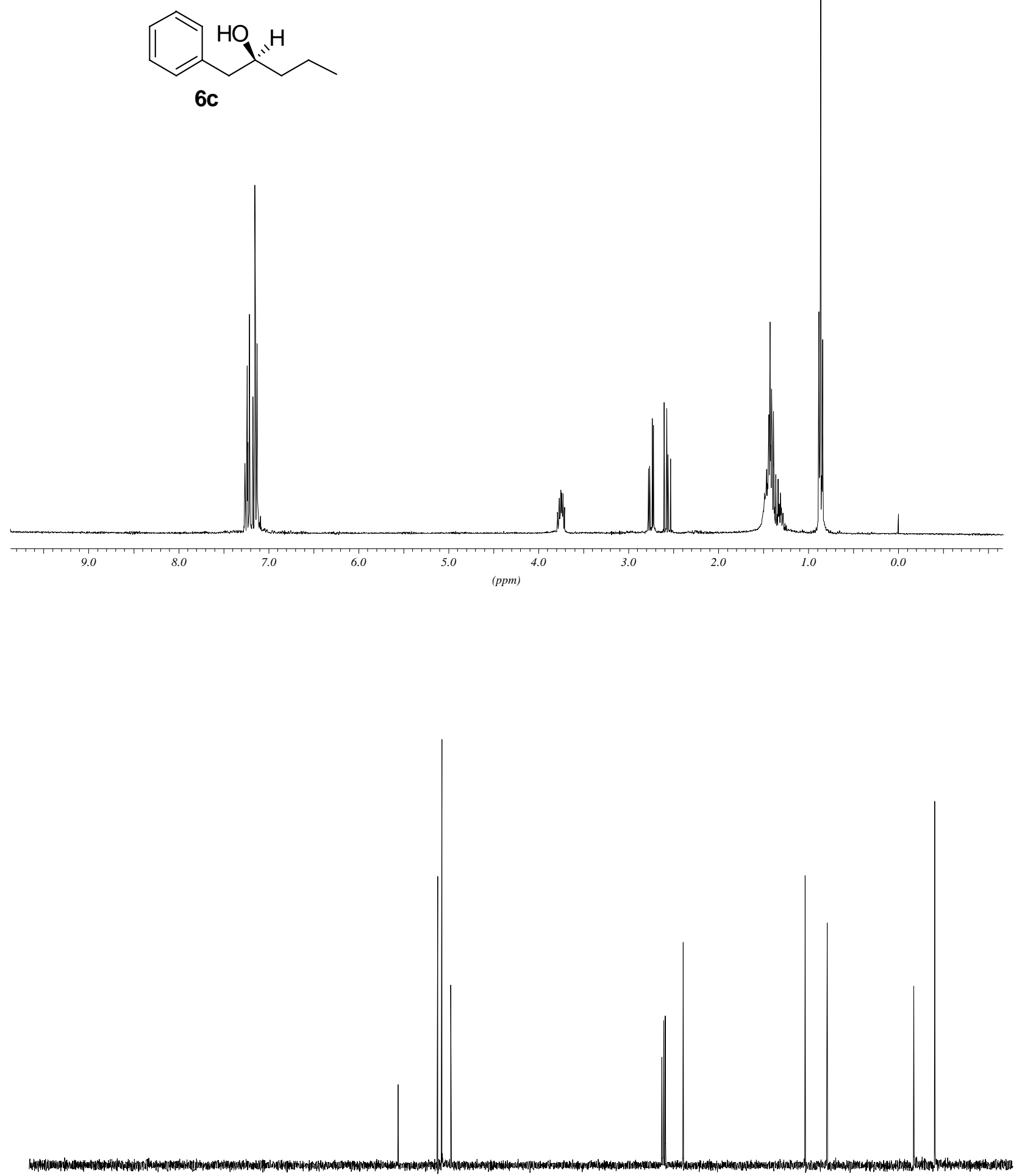


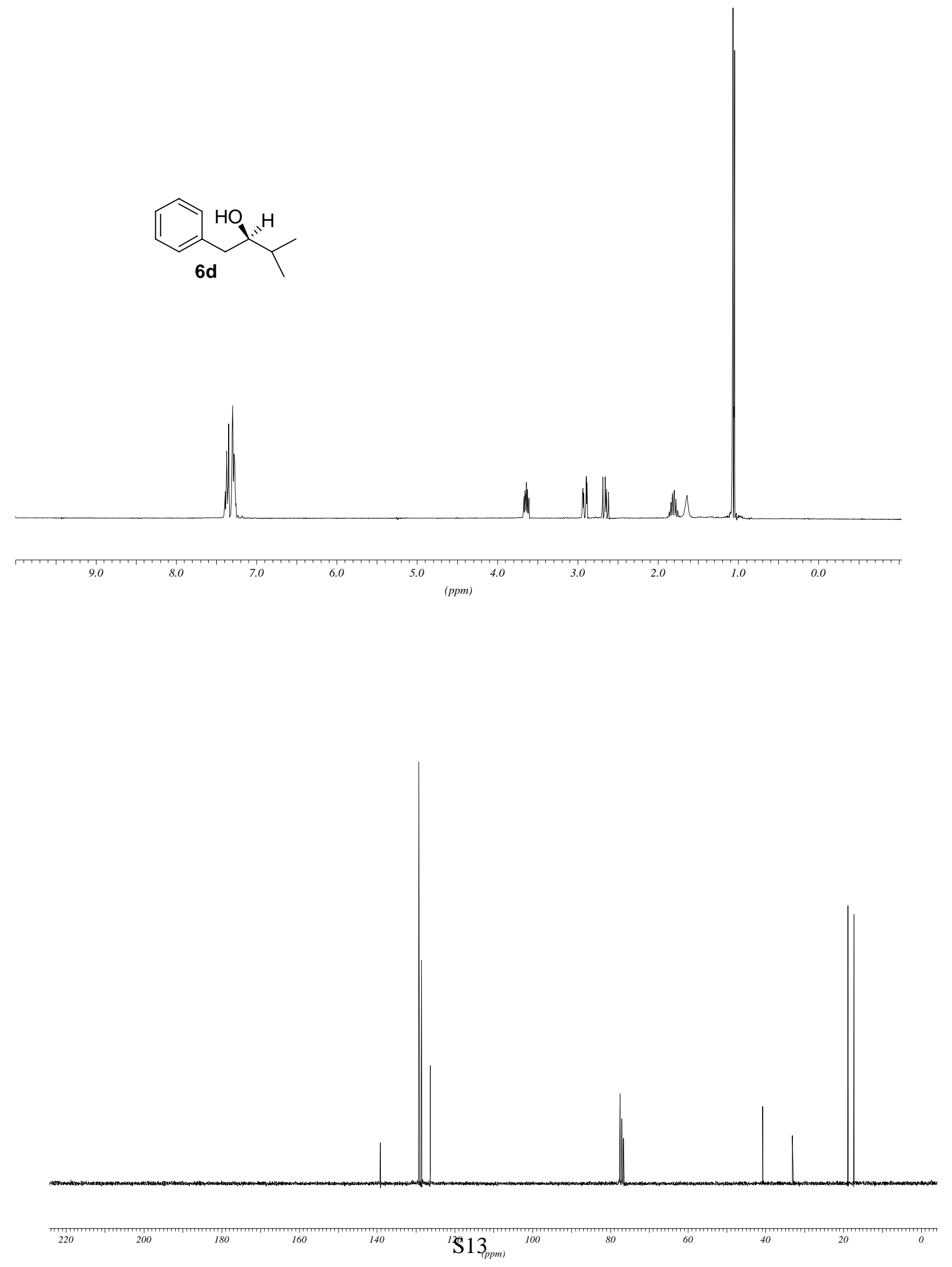




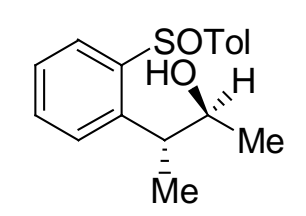

$7 a$
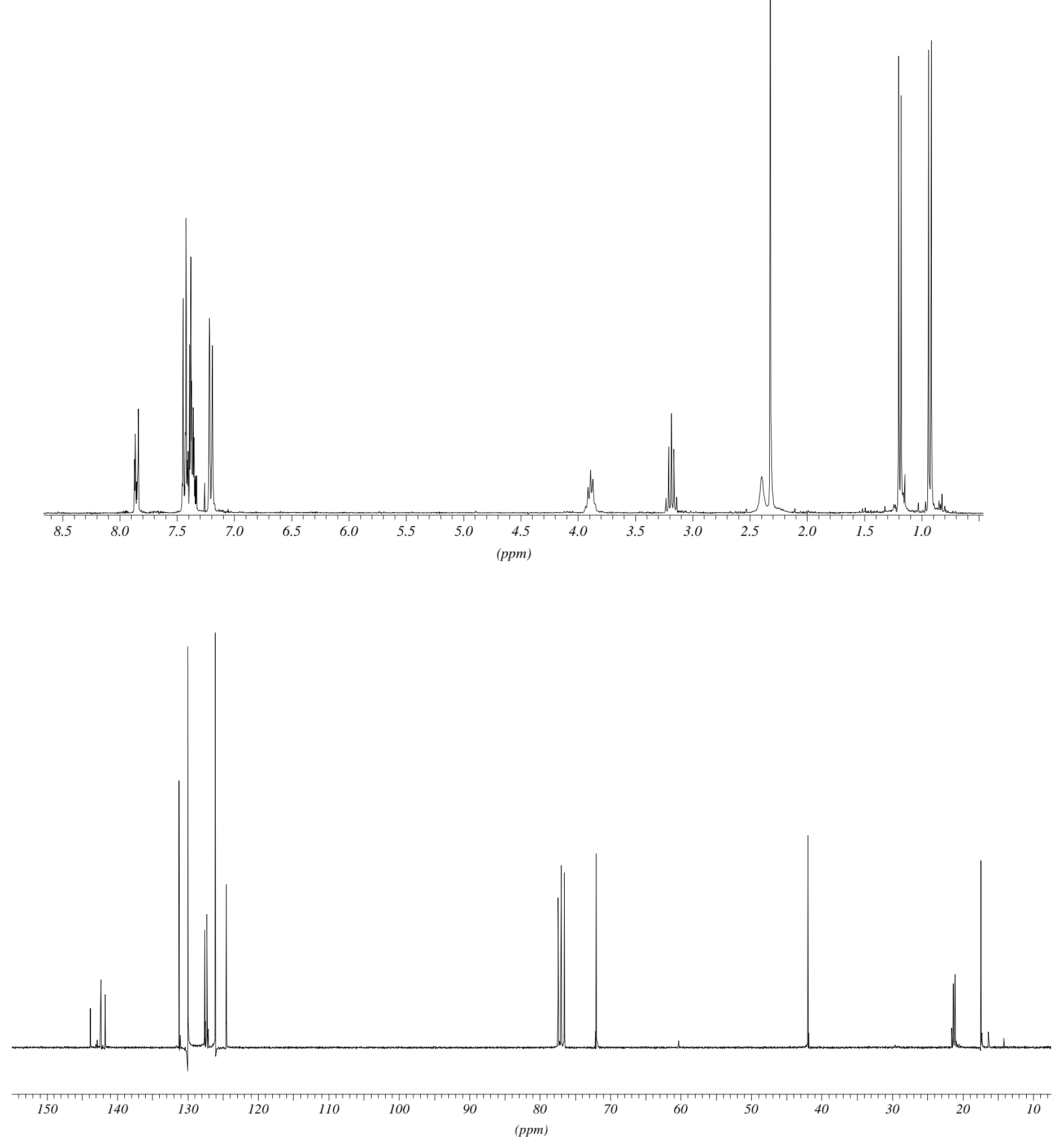


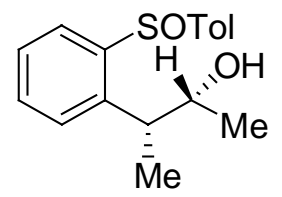

$8 a$
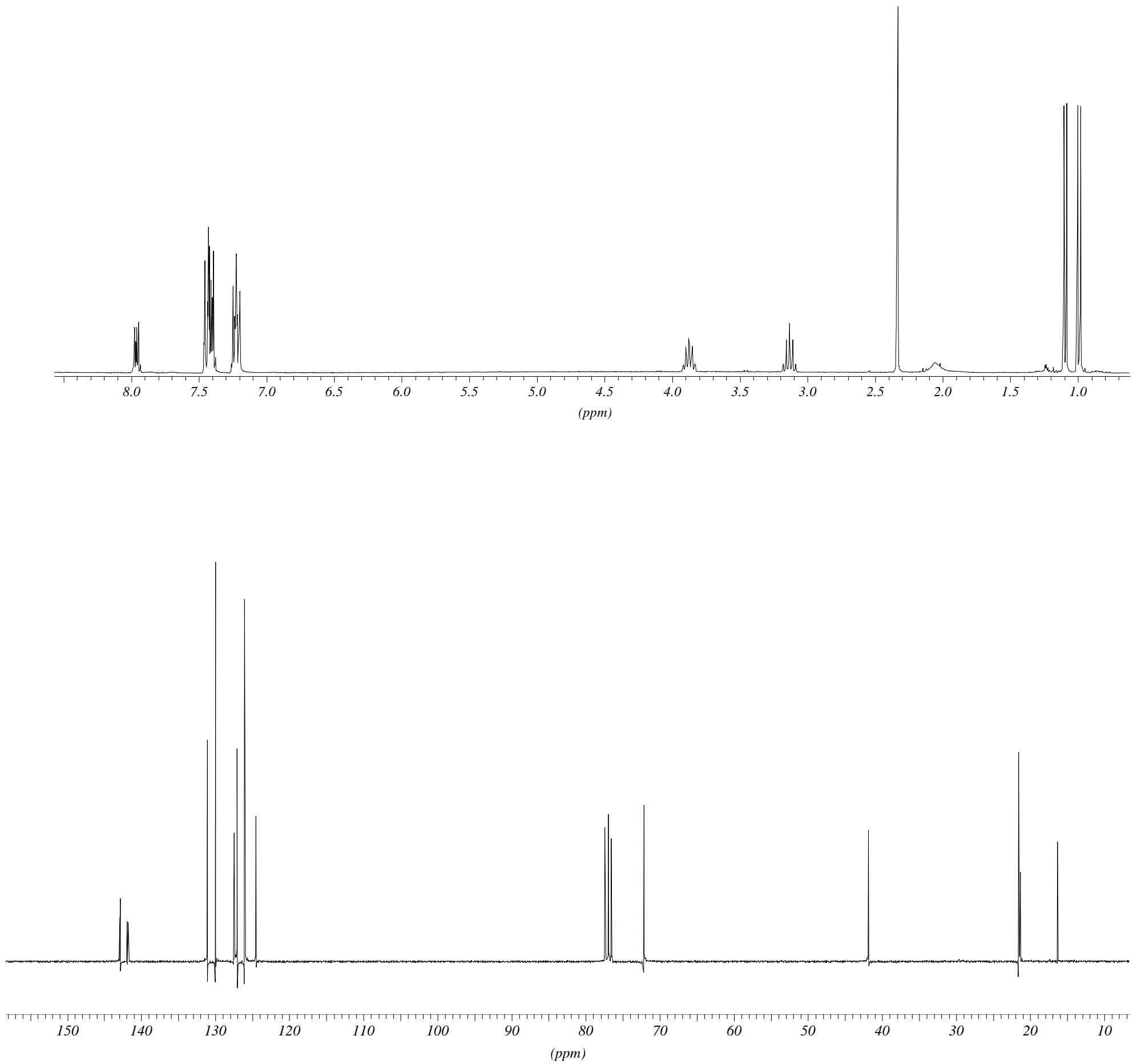


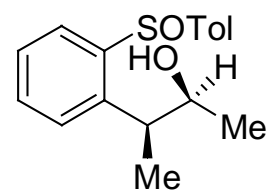

9a
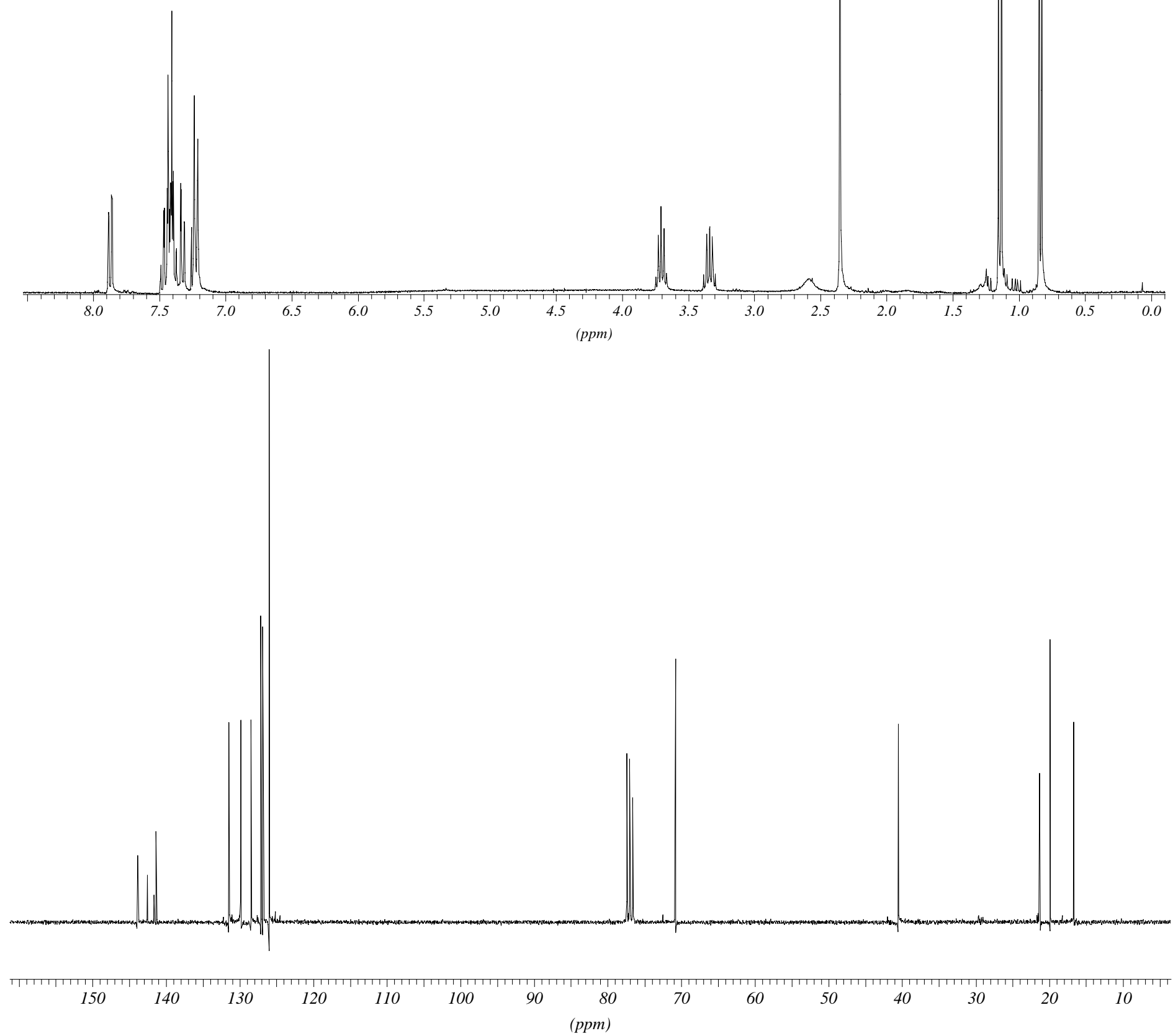

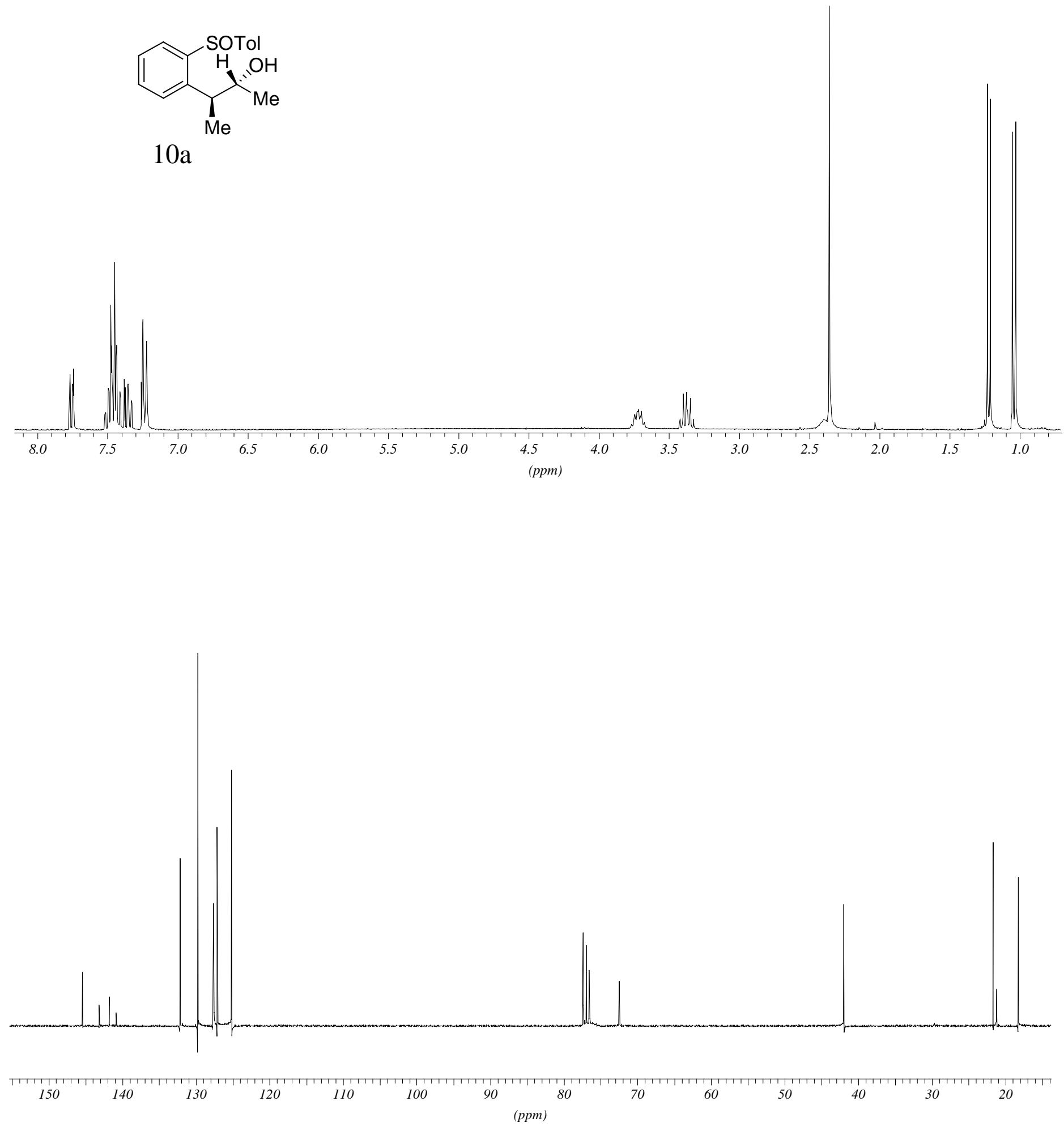


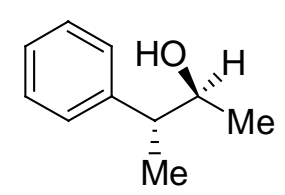

11

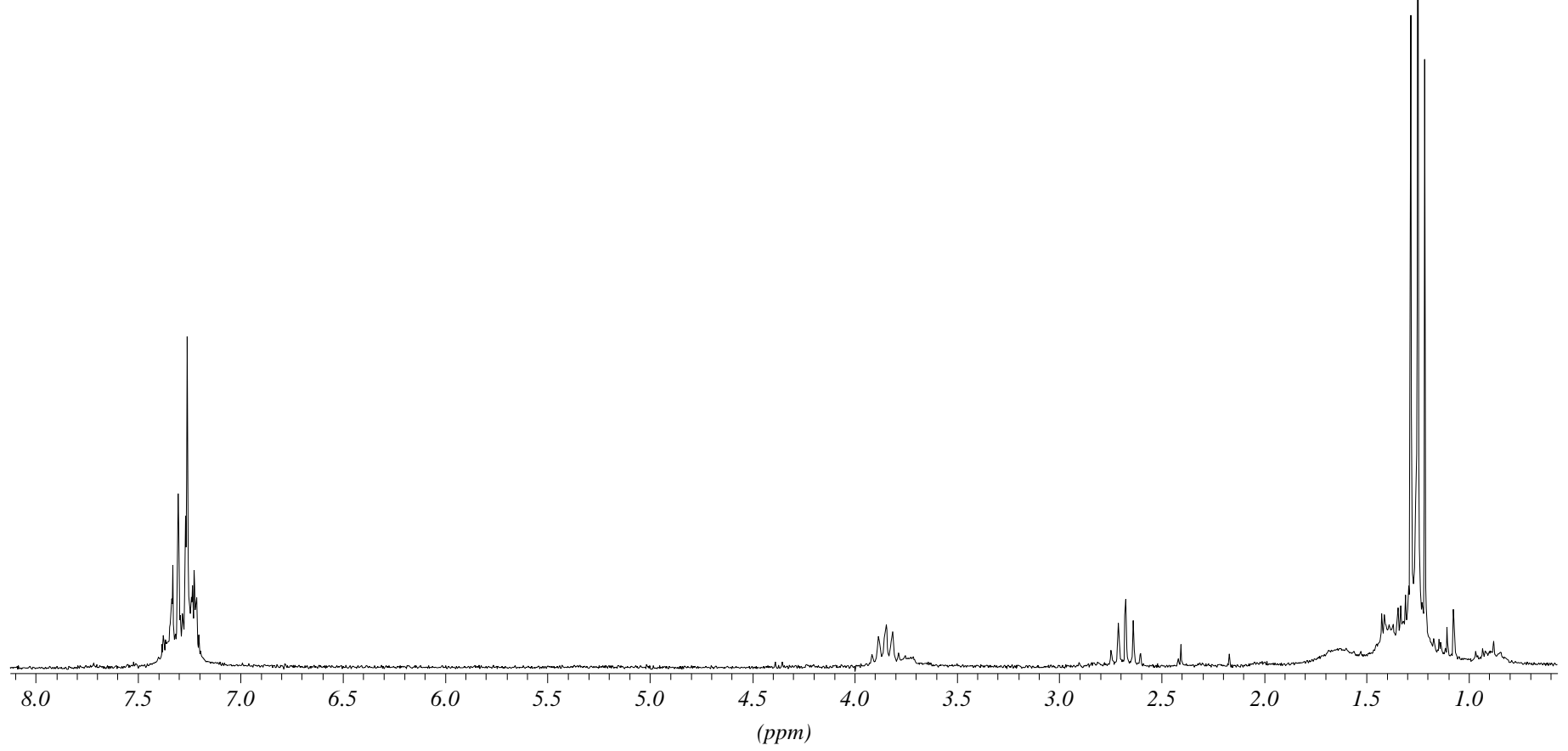

